\title{
Exploring an Architectural Framework for Human-Building Interaction via a Semi-Immersive Cross-Reality Methodology
}

\author{
Supplemental Material
}

\author{
Binh Vinh Duc Nguyen \\ alex.nguyen@kuleuven.be \\ Research[x]Design, Department of \\ Architecture, KU Leuven \\ Leuven, Belgium
}

\author{
Adalberto L. Simeone \\ adalberto.simeone@kuleuven.be \\ ARIA, Department of Computer \\ Science, KU Leuven \\ Leuven, Belgium
}

\author{
Andrew Vande Moere \\ andrew.vandemoere@kuleuven.be \\ Research[x]Design, Department of \\ Architecture, KU Leuven \\ Leuven, Belgium
}

\section{FIGURE DESCRIPTION}

Detailed descriptions of Figure 4 and 6 in the main paper.

\section{Figure 4}

The deployment of the five conditions in the homes.

(a) The home of $\mathrm{P} 1+\mathrm{P} 2$ has an entrance that opens to a circulation zone (C1) that connects three adjacent functional zones to its right, in the sequential order: a bathroom (F1), a kitchen (F2) and an living area (F3) with a sofa and a dining table. At the end of the hallway is a bedroom (F4). This functional zone is adjacent to a semi-outdoor balcony (F5) to its right, whose door opens to the living area (F3). The bathroom (F1) and bedroom (F4) are enclosed spaces with doors opening to their inside, while the kitchen (F2) and the living area (F3) are open spaces connecting directly to the circulation zone (C1). There is a wall separating the kitchen (F2) and the living area (F3). All interior functional zones (bathroom, kitchen, living area, bedroom) have windows that open to the outside. This home has 7 conditions: $2 \mathrm{MF}, 2 \mathrm{MC}, 1 \mathrm{DFF}$ and 2 DFC. In MF1, the wall stands parallel to the window of the living area F3, covering this window. In MF2, it forms a 40 degree angle at a corner of the living area F3, covering the door opening to the balcony F5. In MC1, it covers the entrance to the kitchen F2 from within the circulation zone $\mathrm{C} 1$, while being slightly rotated (10 degree) compared to the surrounding wall. In $\mathrm{MC} 2$, it stands perpendicular to the direction of the circulation zone $\mathrm{C} 1$, covering the entrance to the bedroom $\mathrm{F} 4$. In DFF, it stands at the boundary between the living area F3 and the balcony F5. In the DFC conditions, it disconnects the entrance from the circulation zone $\mathrm{C} 1$ to the kitchen F2 (DFC1) and the living area F3 (DFC2).

(b) The home of $\mathrm{P} 4+\mathrm{P} 5$ has an entrance that opens to a circulation zone (C1). This small hall has three doors: the front (D1) opens to a toilet (F1), the left (D2) opens to a bedroom (F2), and the right (D3) opens to the main space. This main space has 1 circulation zone (C2) and 5 functional zones. The circulation zone $\mathrm{C} 2$ connects to $\mathrm{C} 1$ through the door D3. To the right of $\mathrm{C} 2$ are two adjacent functional zones: a dining area with a dining table (F3) and a living area with a large sofa and the television (F4). To the left of $\mathrm{C} 2$ are two adjacent functional zones: a kitchen (F5) and an area to practice and perform music with a piano, bookshelves and a small sofa (F6). The dining area (F3), living area (F4), and music area (F6) form an open space that is accessible to a balcony (F7). The kitchen (F5) is an enclosed space with a door connecting to $\mathrm{C} 2$. This home has 7 conditions: 2 MF, 1 MC, 1 DFF, 2 DFC and 1 CFF. In MF1, the wall stands inside the dining area F3, parallel to the boundary between F3 and the living area F4. In MF2, it stands inside the music area F6, behind the piano and perpendicular to a wall with a window. In $\mathrm{MC}$, it forms a 30 degree angle within $\mathrm{C} 1$, to cover the entrances to the toilet F1 and the bedroom F2. In DFF, it stands at the boundary between the dining area F3 and living area F4, dividing them. In the DFC conditions, it disconnects the entrance from the circulation zone $\mathrm{C} 2$ to the living area F4 (DFC1) and the music area F6 (DFC2). In $\mathrm{CFF}$, it is perpendicular to the boundary between the dining area F3 and living area F4.

\section{Figure 6}

Potential locations of the responsive wall to afford a Focus atmosphere in a prototypical floor plan.

The circulation zone $\mathrm{C} 1$ is a horizontal rectangle located at the bottom of the floor plan. The functional zones F1 (top-right) and F2 (top-left) are two adjacent vertical rectangles at the top of C1. There are two doors in the floor plan, one at the bottom-right (D1) and one at the bottom-left (D2), both opening to C1. The top wall of the floor plan has a window, which is inside the functional zone F2. There are a sofa and a television inside functional F1. The sofa is adjacent to the boundary between $\mathrm{F} 1$ and $\mathrm{C} 1$, while the television is on the opposite wall at the top of the floor plan, facing the sofa and door D1. The functional zone F2 has a working table and a chair. This table-chair set leans on the left wall of the floor plan, facing zone F1. Subsequently, door D2 is on the right side of the working table. In MF, the wall is inside F2, parallel to the left wall and right in front of the working table. In MC, the wall is inside $\mathrm{C} 1$, forming a 10 degree angle to disrupt the circulation between D1 and D2. In DFF, the wall is at the boundary between F1 and F2. In DFC, it is at the boundary between $\mathrm{F} 2$ and $\mathrm{C}$.

\section{SUPPLEMENTAL DATA}

Figure 1 visualizes the full questionnaire results of the five condition, and Table 1, 2, 3, 4, 5 show these results in numeric data. Table 6 shows the frequencies of how each architectural qualities and their affordances were mentioned in the semi-structured interview. Figure 2 shows the mean time that the participants spent in each conditions, categorized based on their behavior.

\section{SUPPLEMENTAL FIGURES}

Supplemental figures provide further visualization, such the virtual simulation of the homes (Figure 4), the UI (Figure 5), screenshots of the conditions (Figure 6), spatial zonings of the homes (Figure 7), and the deployment of the condition (Figure 8 to 13). 
MF

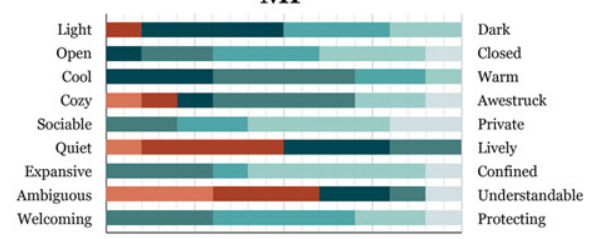

MC

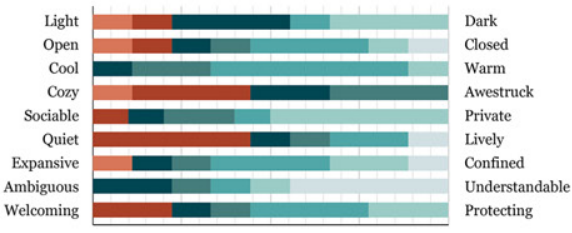

DFF

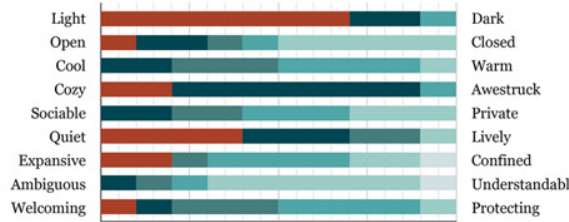

DFC

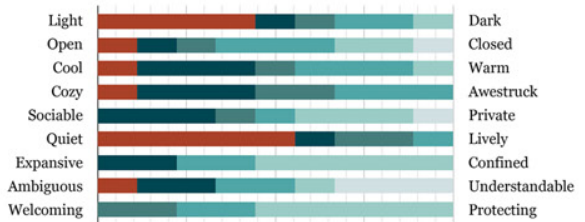

CFF

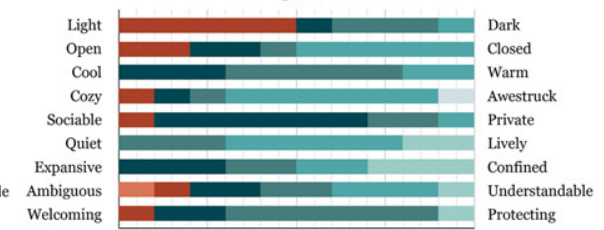

Figure 1: Questionnaire results of the conditions as stacked bar chart.

Table 1: Questionnaire result of condition MF (\%)

\begin{tabular}{lrrrrrrrl}
\hline & -3 & -2 & -1 & 0 & 1 & 2 & 3 & \\
\hline Light & & 12 & 38 & & 31 & 19 & & Dark \\
Open & & & 10 & 20 & 30 & 30 & 10 & Closed \\
Cool & & & 30 & 45 & 15 & 10 & & Warm \\
Cozy & 10 & 10 & 15 & 40 & & 20 & 5 & Awestruck \\
Sociable & & & & 22 & 20 & 38 & 20 & Private \\
Quiet & 10 & 40 & 33 & 17 & & & & Lively \\
Expansive & & & & 30 & 11 & 49 & 10 & Confined \\
Ambiguous & 30 & 32 & 18 & 10 & & & 10 & Understandable \\
Welcoming & & & & 31 & 39 & 20 & 10 & Protecting \\
\hline
\end{tabular}

Table 2: Questionnaire result of condition MC (\%)

\begin{tabular}{lrrrrrrrl}
\hline & -3 & -2 & -1 & 0 & 1 & 2 & 3 & \\
\hline Light & 12 & 10 & 34 & & & 10 & 33 & Dark \\
Open & 12 & 11 & 13 & 9 & 33 & 10 & 12 & Closed \\
Cool & & & 10 & 23 & 56 & 11 & & Warm \\
Cozy & 9 & 35 & 23 & 33 & & & & Awestruck \\
Sociable & & 8 & 12 & 21 & 8 & 51 & & Private \\
Quiet & & 45 & 10 & 9 & 25 & & 11 & Lively \\
Expansive & 9 & & 13 & 10 & 34 & 23 & 11 & Confined \\
Ambiguous & & & 21 & 12 & 12 & 10 & 45 & Understandable \\
Welcoming & 23 & 9 & 13 & 31 & 24 & & Protecting \\
\hline
\end{tabular}

Table 3: Questionnaire result of condition DFF (\%)

\begin{tabular}{|c|c|c|c|c|c|c|c|c|}
\hline & -3 & -2 & -1 & 0 & 1 & 2 & 3 & \\
\hline Light & & 70 & 22 & & 8 & & & Dark \\
\hline Open & & 10 & 20 & 11 & 9 & 50 & & Closed \\
\hline Cool & & & 22 & 28 & 41 & 9 & & Warm \\
\hline Cozy & & 21 & 70 & & 9 & & & Awestruck \\
\hline Sociable & & & 22 & 18 & 33 & 27 & & Private \\
\hline Quiet & & 39 & 31 & 20 & & 10 & & Lively \\
\hline Expansive & & 20 & & 11 & 40 & 21 & 10 & Confined \\
\hline Ambiguous & & & 9 & 11 & 12 & 60 & 8 & Understandable \\
\hline Welcoming & & 8 & 9 & 31 & 42 & 10 & & Protecting \\
\hline
\end{tabular}

Table 4: Questionnaire result of condition DFC (\%)

\begin{tabular}{|c|c|c|c|c|c|c|c|c|}
\hline & -3 & -2 & -1 & 0 & 1 & 2 & 3 & \\
\hline Light & & 43 & 11 & 12 & 24 & 10 & & Dark \\
\hline Open & & 9 & 10 & 12 & 33 & 25 & 11 & Closed \\
\hline Cool & & 12 & 35 & 10 & 34 & 9 & & Warm \\
\hline Cozy & & 12 & 30 & 25 & 33 & & & Awestruck \\
\hline Sociable & & & 35 & 13 & 11 & 30 & 11 & Private \\
\hline Quiet & & 57 & 12 & 21 & 10 & & & Lively \\
\hline Expansive & & & 24 & & 20 & 56 & & Confined \\
\hline Ambiguous & & 12 & 20 & & 24 & 10 & 34 & Understandable \\
\hline Welcoming & & & & 20 & 22 & 58 & & Protecting \\
\hline
\end{tabular}

Table 5: Questionnaire result of condition CFF (\%)

\begin{tabular}{|c|c|c|c|c|c|c|c|c|}
\hline & -3 & -2 & -1 & 0 & 1 & 2 & 3 & \\
\hline Light & & 50 & 11 & 29 & 10 & & & Dark \\
\hline Open & & 18 & 22 & 10 & 50 & & & Closed \\
\hline Cool & & & 27 & 53 & 20 & & & Warm \\
\hline Cozy & & 8 & 10 & 11 & 61 & & 10 & Awestruck \\
\hline Sociable & & 11 & 60 & 20 & 9 & & & Private \\
\hline Quiet & & & & 28 & 52 & 20 & & Lively \\
\hline Expansive & & & 30 & 22 & 18 & 30 & & Confined \\
\hline Ambiguous & 9 & 11 & 22 & 20 & 30 & 8 & & Understandable \\
\hline Welcoming & & 8 & 20 & 62 & & 10 & & Protecting \\
\hline
\end{tabular}


Table 6: Frequency of verbal utterances of architectural qualities in the experiment and in each condition

\begin{tabular}{|c|c|c|c|c|c|c|c|c|}
\hline Quality & & Affordances & & MF & $\mathrm{MC}$ & DFF & DFC & $\mathrm{CFF}$ \\
\hline \multirow[t]{3}{*}{ Functionality } & 55 & Preventing existing activities & $15(8 \%)$ & $9(4.5 \%)$ & 0 & 0 & 0 & $7(3.5 \%)$ \\
\hline & $(28 \%)$ & Supporting existing activities & $26(13 \%)$ & $1(0.5 \%)$ & $5(2.5 \%)$ & $9(4.5 \%)$ & $11(5.6 \%)$ & 0 \\
\hline & & Suggesting new activities to take place & $13(7 \%)$ & 0 & $3(1.5 \%)$ & $5(2.5 \%)$ & $3(1.5 \%)$ & $2(1 \%)$ \\
\hline \multirow[t]{3}{*}{ Visuality } & 52 & Covering available views & $32(16 \%)$ & $7(3.5 \%)$ & $4(2 \%)$ & $8(4 \%)$ & $10(5.1 \%)$ & $3(1.5 \%)$ \\
\hline & $(26 \%)$ & Creating directional views & $7(4 \%)$ & $3(1.5 \%)$ & 0 & $4(2 \%)$ & 0 & 0 \\
\hline & & Preventing unwanted views from outside & $13(7 \%)$ & $3(1.5 \%)$ & $7(3.5 \%)$ & 0 & $1(0.5 \%)$ & $2(1 \%)$ \\
\hline \multirow[t]{3}{*}{ Connectivity } & 42 & Disconnecting existing connections & $20(10 \%)$ & $3(1.5 \%)$ & $4(2 \%)$ & $7(3.5 \%)$ & $6(3 \%)$ & 0 \\
\hline & $(21 \%)$ & Changing existing connections & $16(8 \%)$ & $1(0.5 \%)$ & $7(3.5 \%)$ & 0 & $4(2 \%)$ & $4(2 \%)$ \\
\hline & & Opening new connections & $6(3 \%)$ & 0 & $4(2 \%)$ & 0 & $1(0.5 \%)$ & $1(0.5 \%)$ \\
\hline \multirow[t]{3}{*}{ Materiality } & 30 & Reflecting light & $19(10 \%)$ & $4(2 \%)$ & $3(1.5 \%)$ & $5(2.5 \%)$ & $5(2.5 \%)$ & $2(1 \%)$ \\
\hline & $(15 \%)$ & Increasing airflow & $8(4 \%)$ & $2(1 \%)$ & 0 & $5(2.5 \%)$ & 0 & $1(0.5 \%)$ \\
\hline & & Reflecting sound & $3(2 \%)$ & $3(1.5 \%)$ & 0 & 0 & 0 & 0 \\
\hline \multirow[t]{2}{*}{ Uniformity } & 19 & Separating zones into coherent spaces & $11(6 \%)$ & $4(2 \%)$ & 0 & $6(3 \%)$ & $1(0.5 \%)$ & 0 \\
\hline & $(10 \%)$ & Hiding non-belonging elements & $8(4 \%)$ & $4(2 \%)$ & 0 & $3(1.5 \%)$ & 0 & $1(0.5 \%)$ \\
\hline \multirow[t]{2}{*}{ Sum } & 198 & & 198 & 44 & 37 & 52 & 42 & 23 \\
\hline & $100 \%$ & & $100 \%$ & $22.2 \%$ & $18.7 \%$ & $26.3 \%$ & $21.2 \%$ & $11.6 \%$ \\
\hline
\end{tabular}

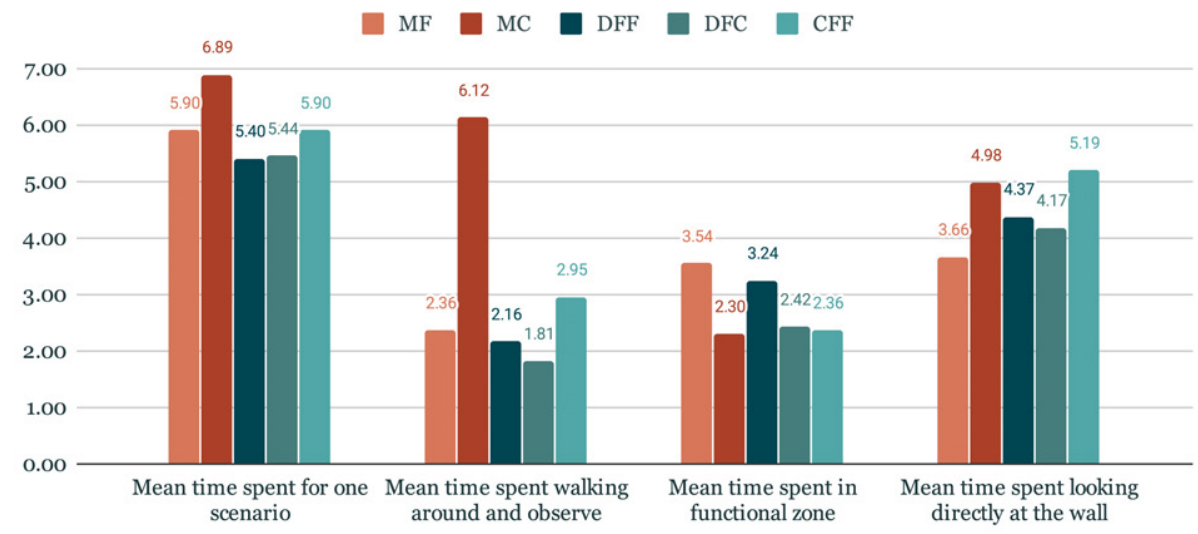

Figure 2: Mean time spent of the participants in five conditions (minute).
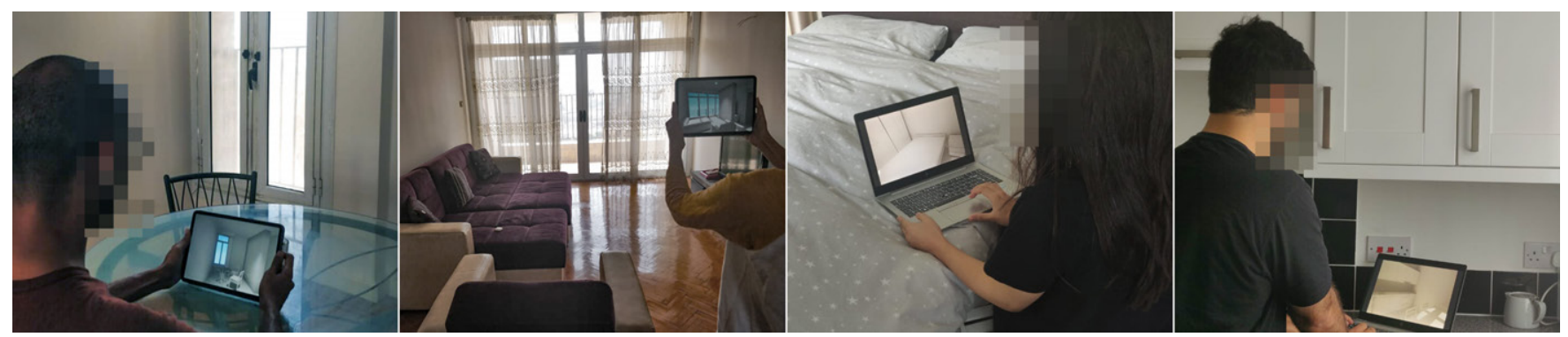

Figure 3: The participants experiencing the semi-immersive mixed reality simulation of their own homes. From left to right: participant P1, P3, P6 and P7. 

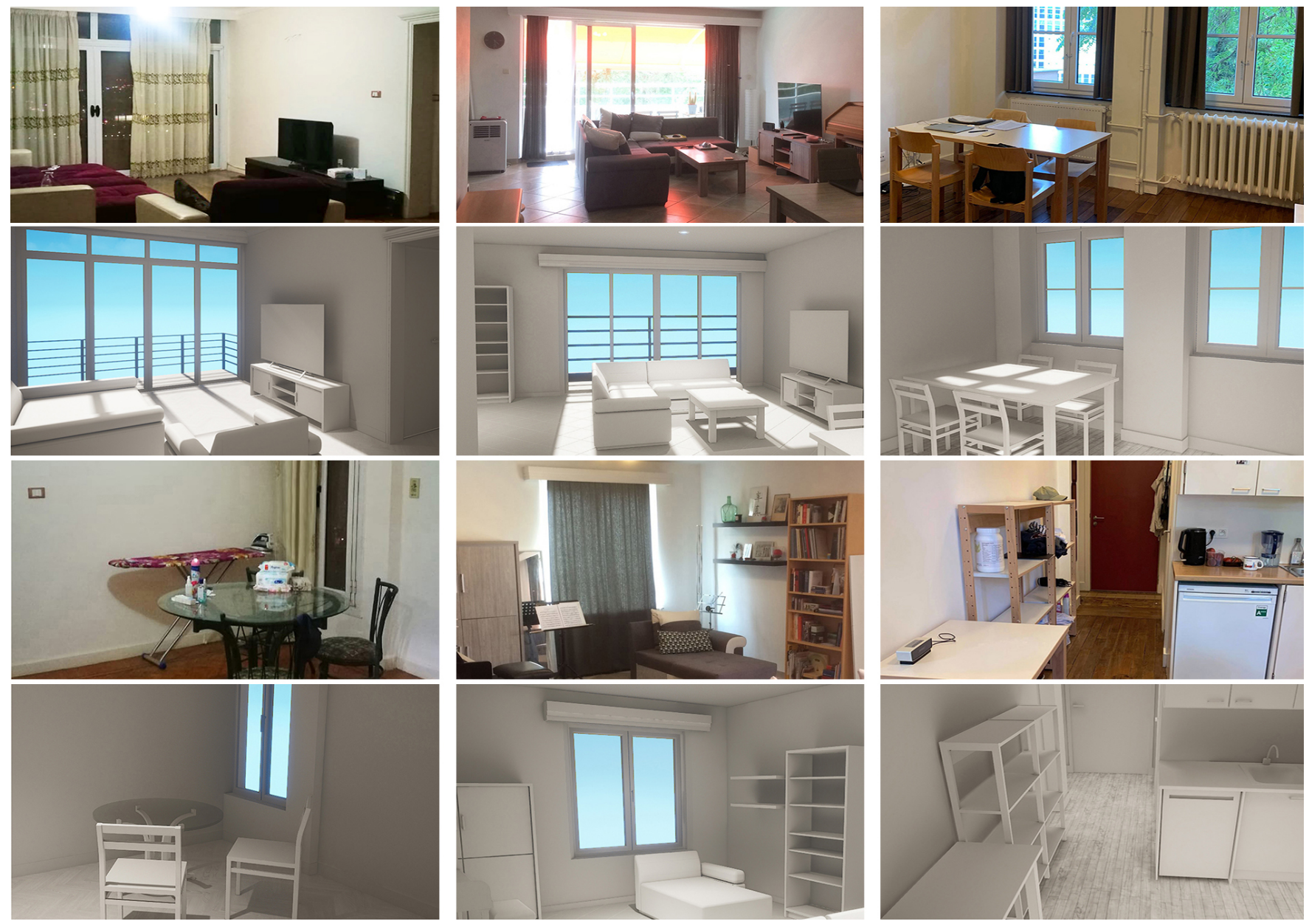

Figure 4: The differences between the real homes of the participants and their abstracted virtual simulations, from left to right: the homes of Participants 3, Participant 4 and 5, and Participant 6.
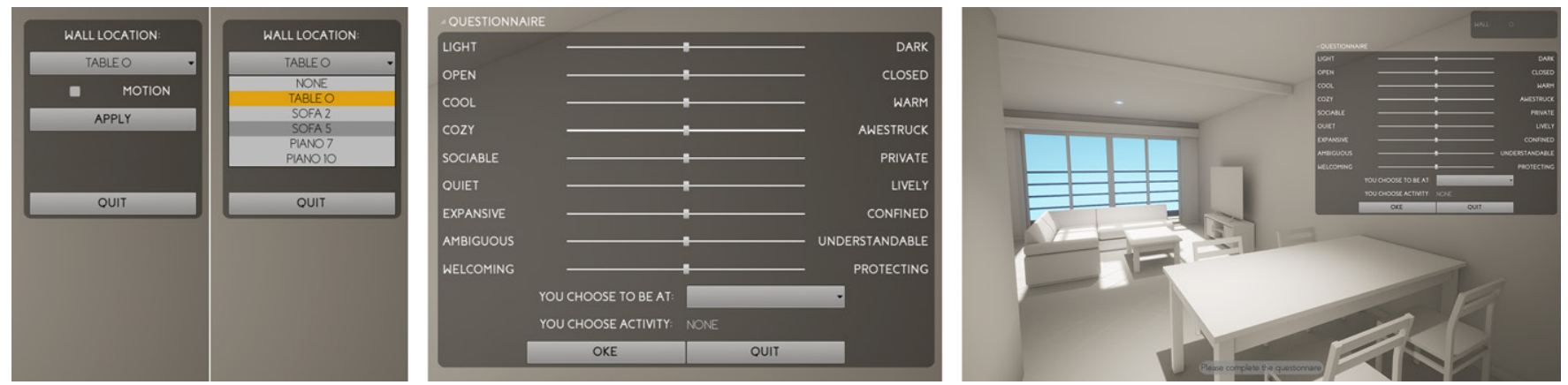

Figure 5: From left to right: The UI that allows participant to control the wall, the questionnaire, and the questionnaire integrated inside the simulation window. 


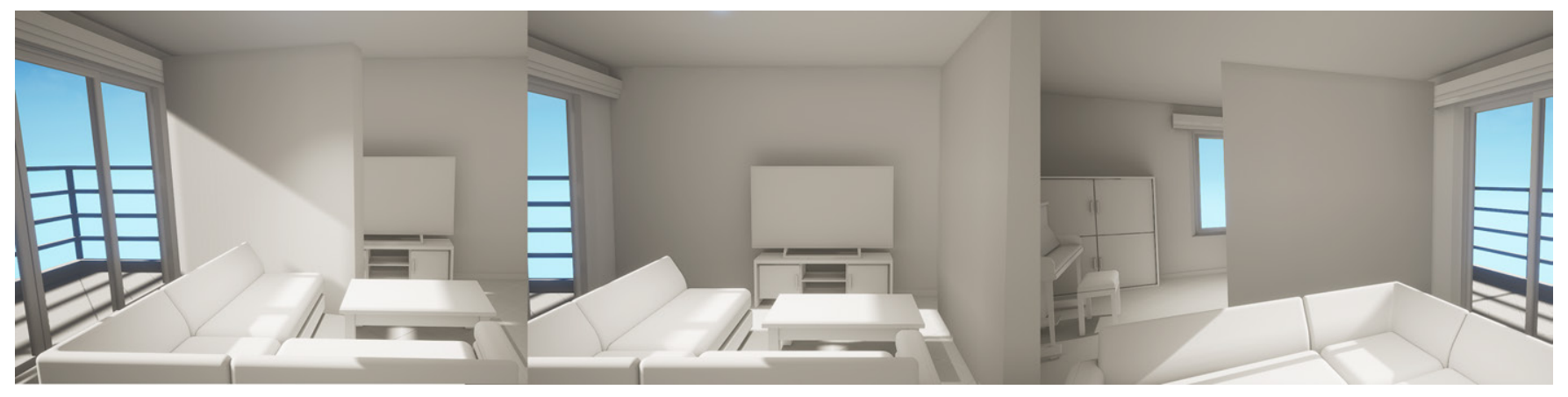

Figure 6: Three different conditions implemented in the Living zone of the homes of participant P4+P5, from left to right: MF, DFF, DFC.

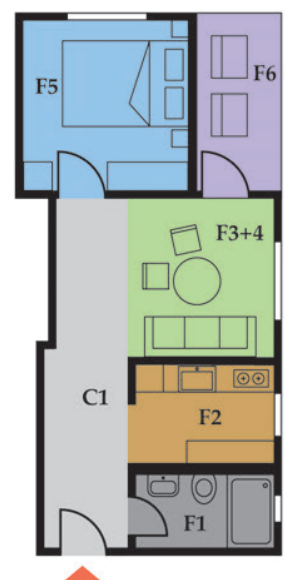

(a)

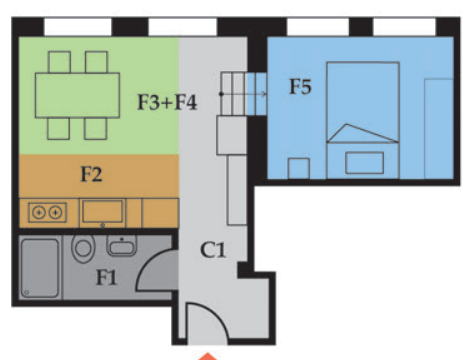

(d)

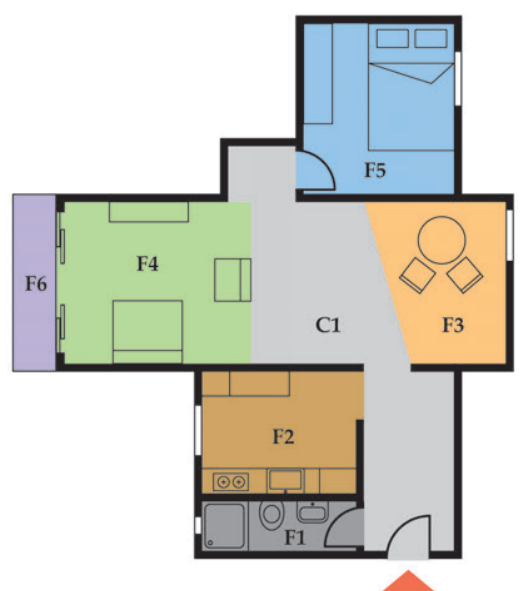

(b)

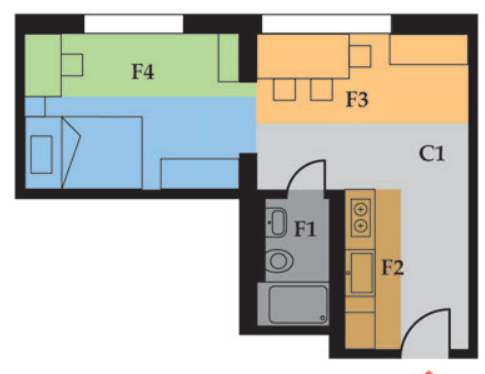

(e)
F1: Toilet

F2: Kitchen

F3: Dining zone

F4: Living zone

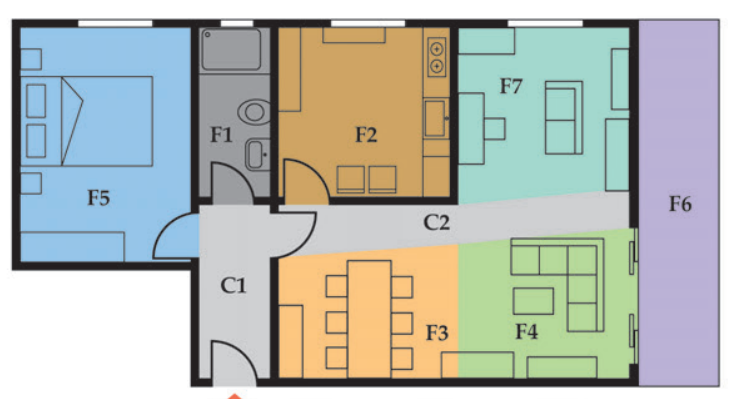

(c)

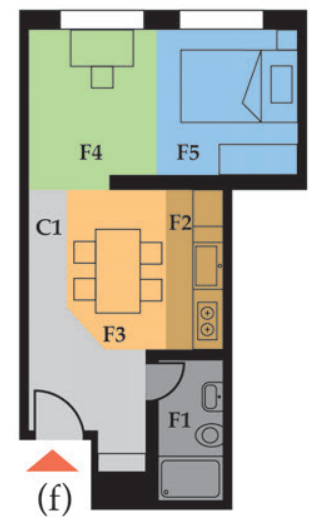

Figure 7: The zoning of the homes of participant P1 and P2 (a), P3 (b), P4 and P5 (c), P6 (d), P7 (e) and P8 (f), showing the diversity of how the zones are configured, and the predominating quantity and area of functional zones compared to circulation zones. 


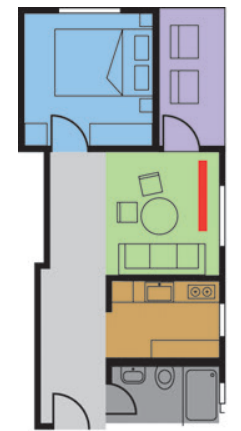

MF
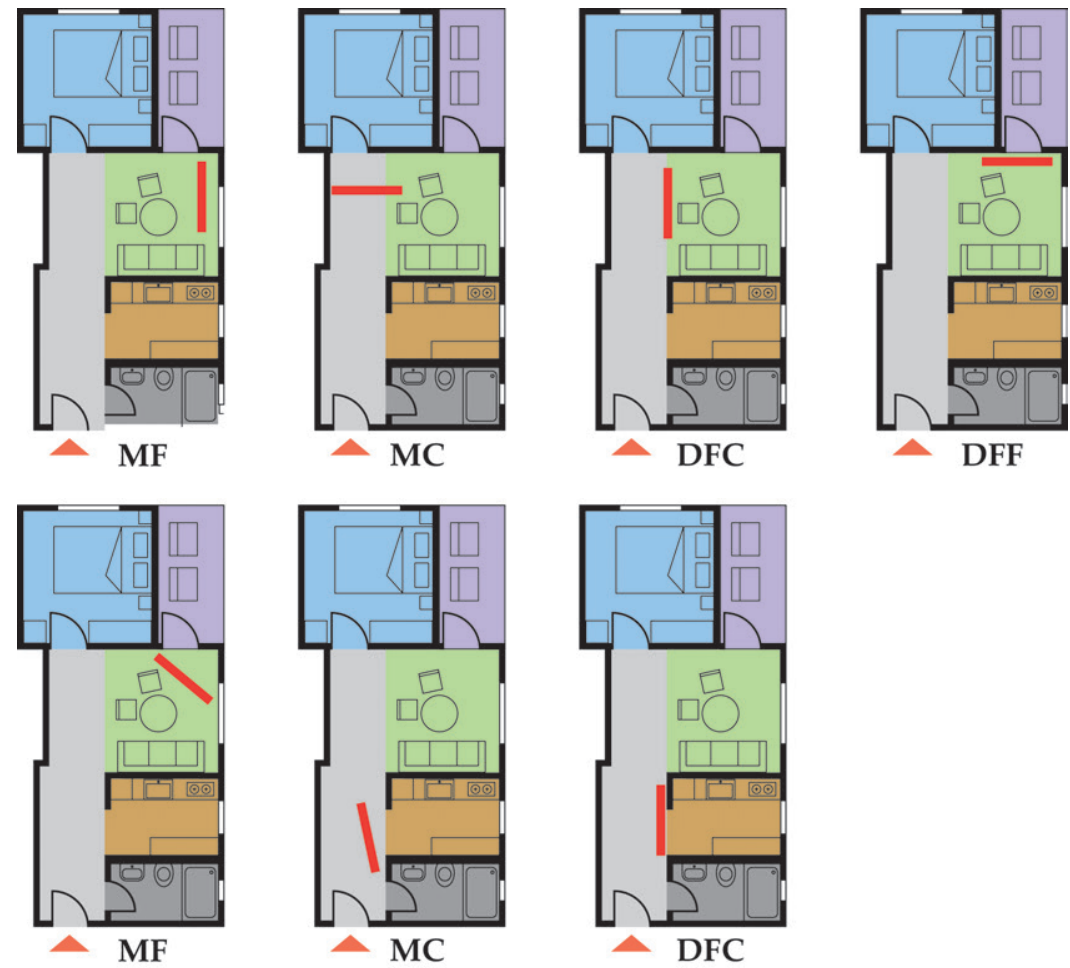

$\triangle$ DFC

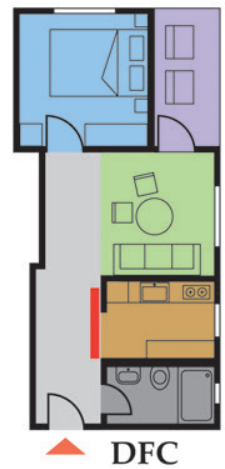

Figure 8: The deployment of the five conditions in the homes of P1+P2.
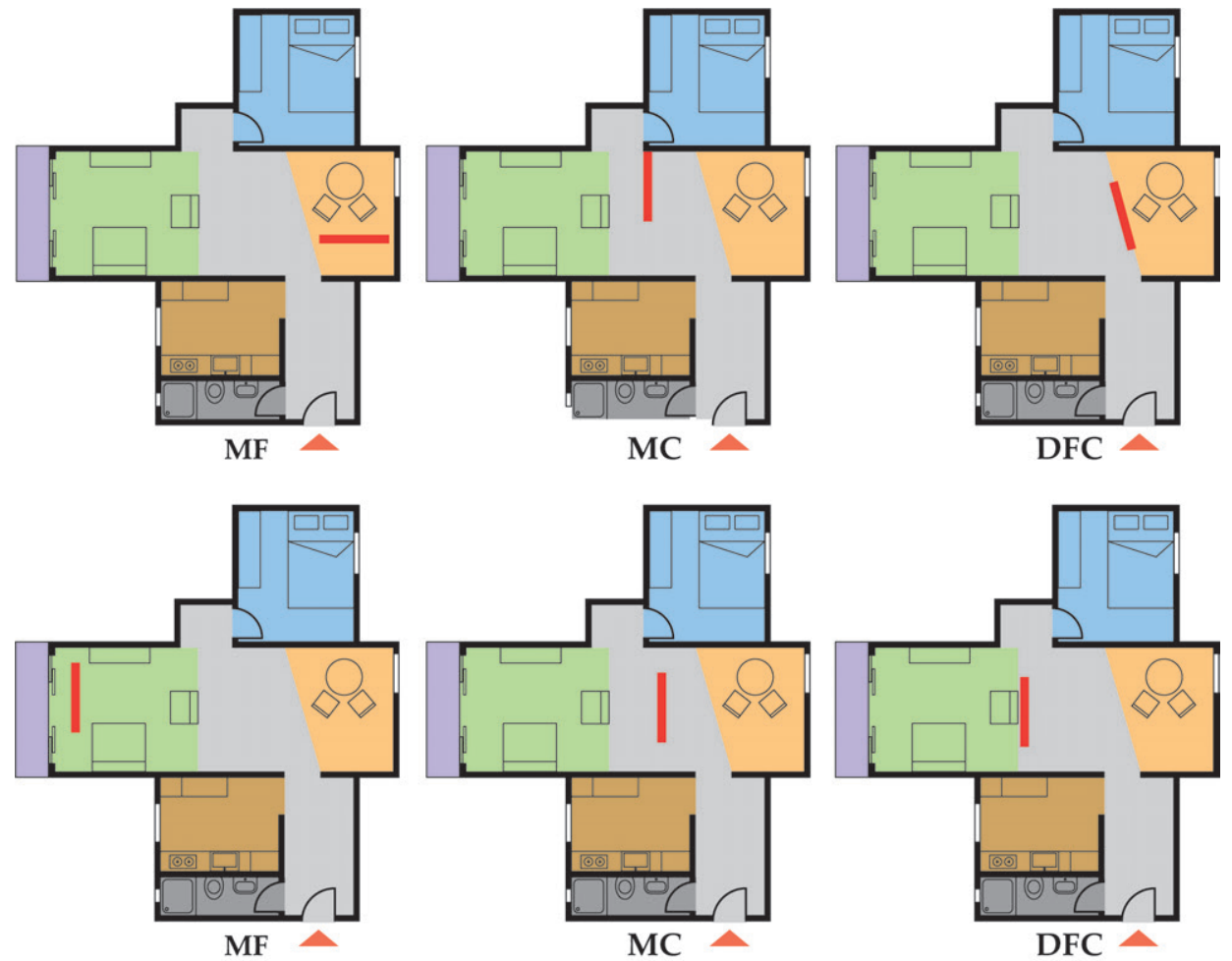

Figure 9: The deployment of the five conditions in the homes of P3. 

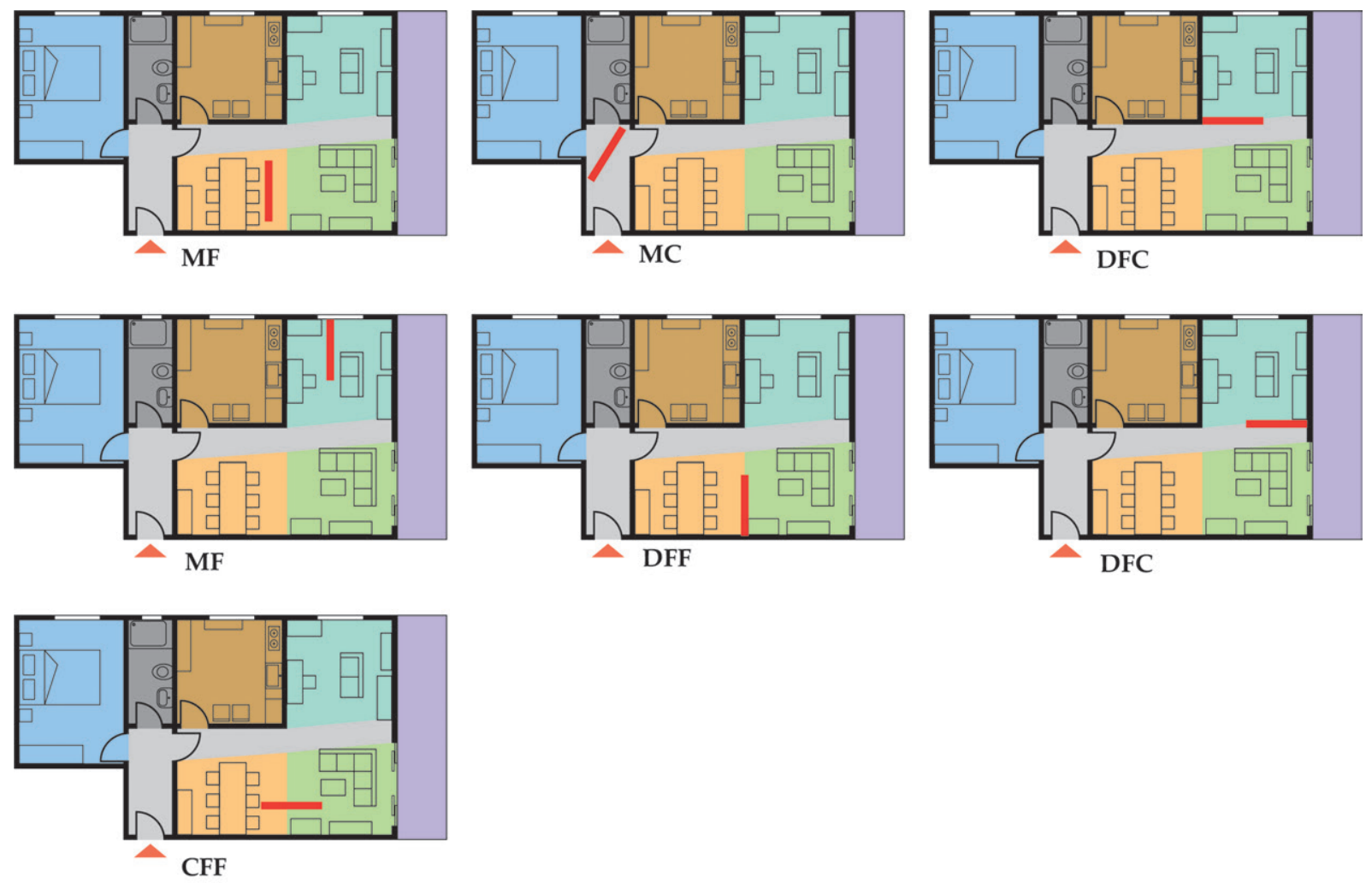

Figure 10: The deployment of the five conditions in the homes of P4+P5.
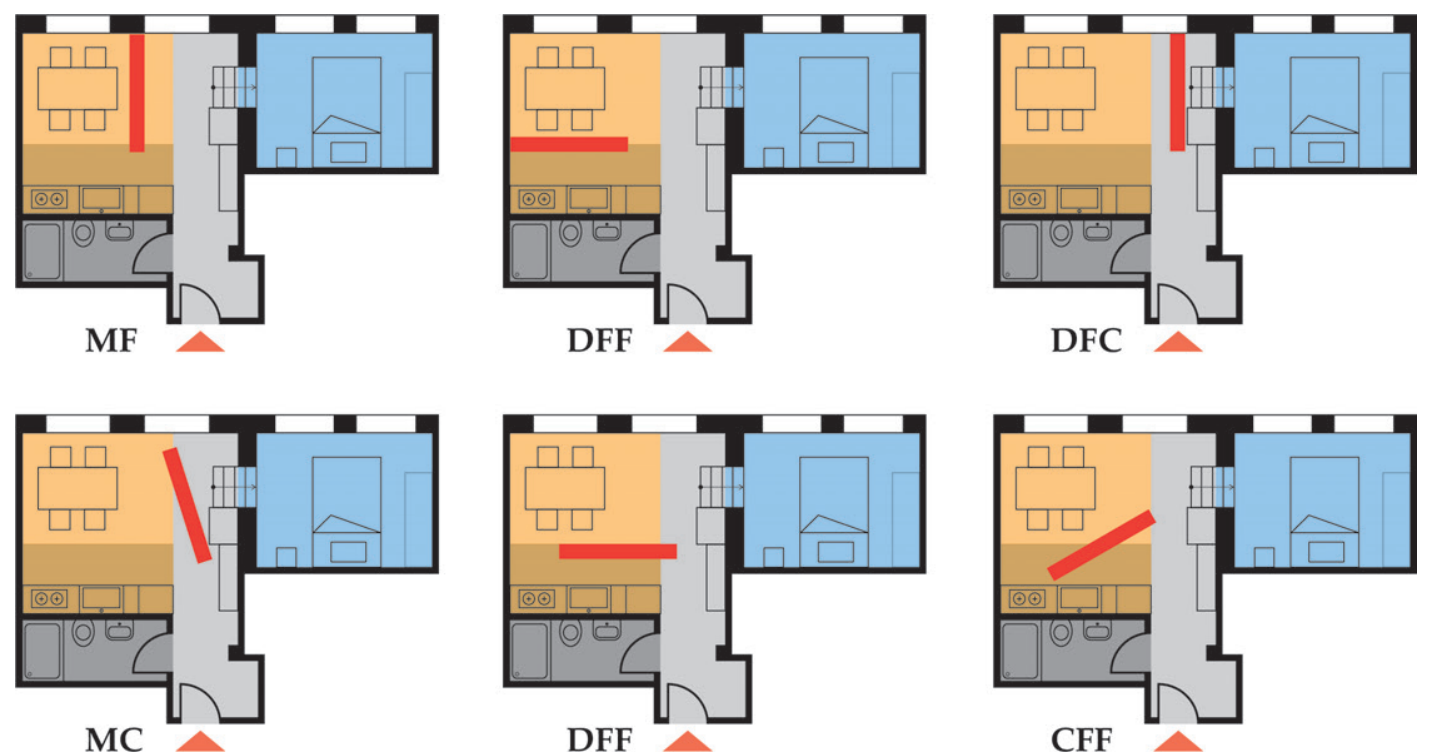

Figure 11: The deployment of the five conditions in the homes of P6. 

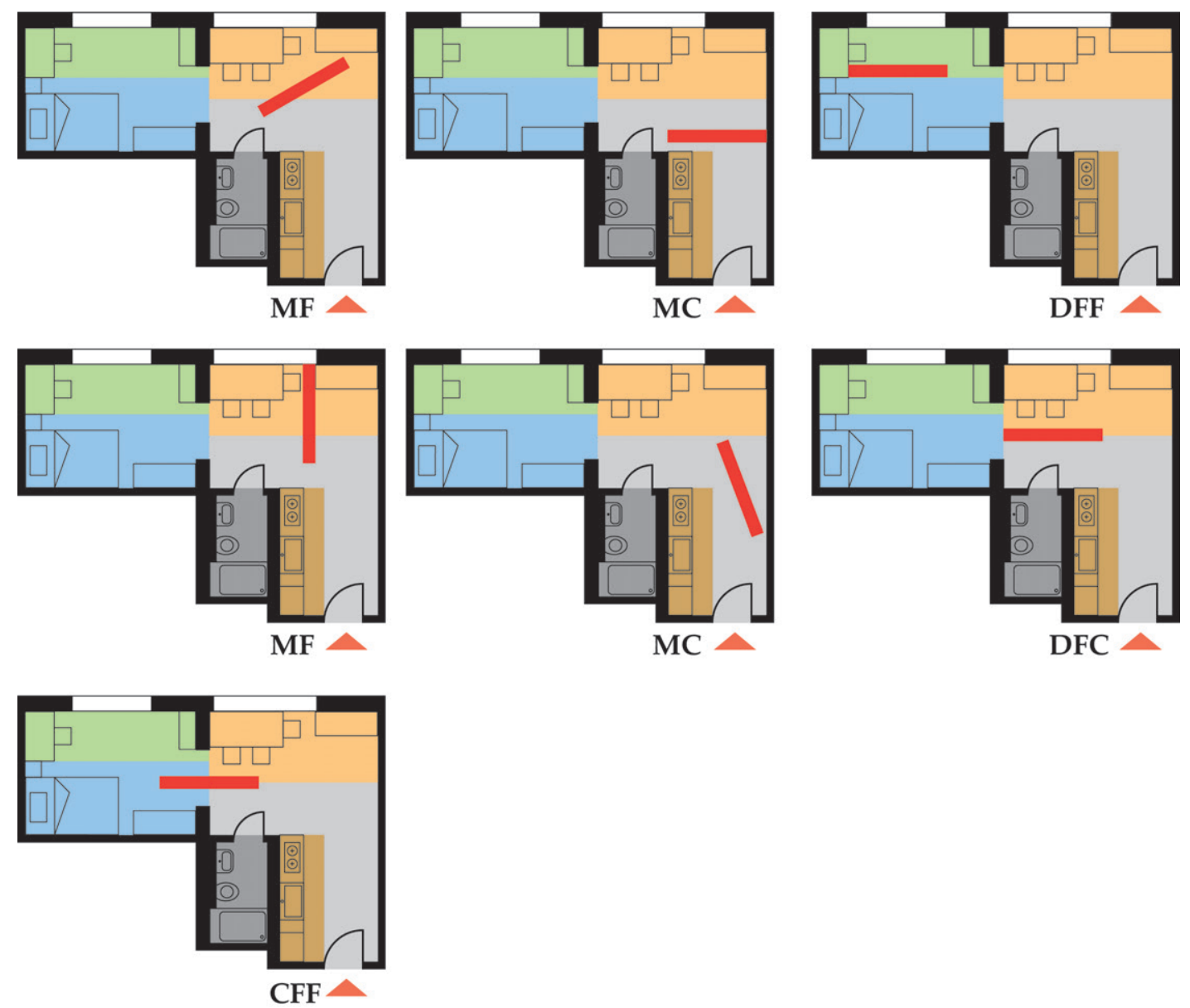

Figure 12: The deployment of the five conditions in the homes of P7.
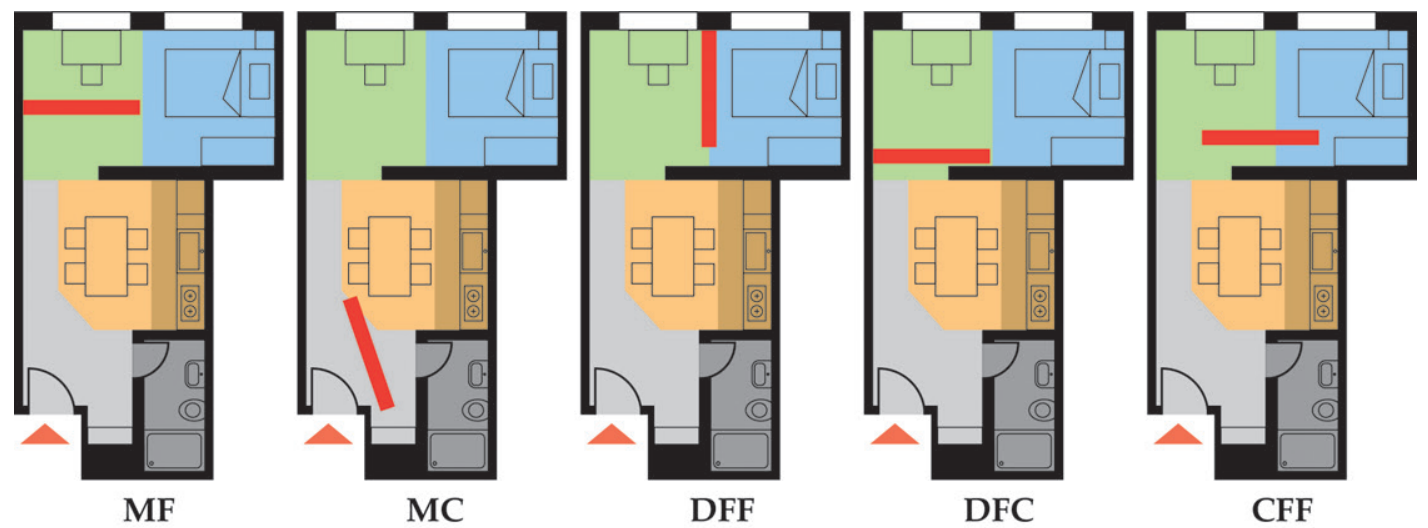

Figure 13: The deployment of the five conditions in the homes of P8. 